\title{
STRICTURE FORMATION FOLLOWING SULPHONAMIDE THERAPY OF GONORRHOEA
}

Case No. 429/45A.-A Norwegian sailor, aged 33 years, attended the Seamen's Dispensary, Avonmouth, in December 1945, complaining of slight urethral discharge and dysuria of increasing severity of three weeks' duration. These symptoms were associated with progressive difficulty in commencing micturition and with terminal dribbling. On the previous day he had had acute retention of urine, which had been relieved by a hot hip bath.

Early history.-He gave a history of four attacks of gonorrhoea : in August 1941, May 1942, September 1943 and November 1944 . On each of these occasions he was treated with sulphonamides only.

(1) The first attack remained untreated for 7 days before he could attend a clinic. A diagnosis of gonorrhoea was made, and he was given an oral sulphonamide preparation, 4 grammes daily for 7 days. There was no intolerance. The discharge had completely cleared by the fifth day. He then rejoined his ship. No further symptoms were noticed until his second attack.

(2 and 3) His second and third infections, both presumed to be gonorrhoeal, were contracted abroad; he was treated on board ship with 3-5 grammes of sulphathiazole daily for 6 days. On both of these occasions his treatment commenced on the day on which the discharge was first noticed; in both cases the discharge gradually subsided in $2-3$ days, no further symptoms being noticed.

(4) In the case of the 1944 infection he attended a clinic during the acute stage only, the diagnosis being microscopically confirmed and the treatment commenced on the day after his discharge had first appeared. He defaulted after taking 30 grammes of sulphathiazole in 5 days. However, he now stated that his discharge had subsided completely by the time that he sailed, some 2 days later.

Later history.-He remained symptom-free until May 1945, when a slight mucoid morning bead was noticed. This persisted for 3 days, then cleared spontaneously. A transient morning discharge, visible for not longer than 3 or 4 days, was subsequently noticed in August and again in September 1945. No further symptoms occurred until the commencement of dysuria in November 1945.

Clinical picture, diagnosis and treatment.- On examination there was found to be congenital atresia of the urinary meatus, which was later found to admit only a $6 \mathrm{~F}$ bougie. There was no urethral discharge and the urine contained a few mucoid threads in the first specimen only. No gross abnormalities were found in the prostate or in the seminal vesicles. It was observed that the patient strained hard on attempting urination and took a considerable time to commence the act, and that the ultimate stream was extremely small. Urethral and prostatic smears showed epithelial cells and an occasional pus cell. No gonococci or other organisms were detected. The Wassermann and Kahn reactions and the complement fixation test for gonorrhoea were all negative.

The presumptive diagnosis of stricture was confirmed by the subsequent instrumentation. The presumably congenital atresia of the urinary meatus, which precluded the passage of an urethroscope at this stage, was overcome and the passage dilated rapidly and easily in the course of a few sittings from $6 \mathrm{~F}$ to $22 \mathrm{~F}$. Exploration of the deeper portion of the urethra revealed a triple stricture : the first, encountered at the bulbo-scrotal junction, was of ring type and easily palpable on the bougie as a thickened band, approximately -inch wide ; the second was situated immediately distal to the superficial layer of the triangular ligament (inferior fascia of the urogenital diaphragm); the third was at the junction of the prostatic and the membranous divisions of the urethra. A $4 \mathrm{~F}$ gum-elastic bougie was passed with difficulty. Gradual dilatation up to 8F was carried out at the first session and, in the ensuing 3 weeks, dilatation up to $22 \mathrm{~F}$ was accomplished. At this stage, the patient returned to his own country, the necessary surveillance having been advised.

This case is interesting because it shows that a subepithelial infiltration can proceed to a "hard " infiltration with stricture formation, despite the apparent success of chemotherapy in the treatment of gonorrhoea. A possible explanation is that spontaneous resolution of subepithelial infiltrates occurs in the vast majority of cases as soon as the infective factor is controlled, but that in those cases in which strictures develop, organisms persist in the partially organized inflammatory deposit and are inaccessible to medication.

It is difficult to determine which of this patient's multiple infections. was productive of these strictures. Congenital strictures may be excluded in view of the patient's previous history. The time lag in 1941, between the onset of the discharge 
and the commencement of treatment, suggests that his first attack was possibly the responsible one. This time lag is all too common amongst seamen who contract gonorrhoea.

On the other hand, the rapid and comparatively easy dilatation of the strictures indicates a more recent origin and the presence of a transitional subepithelial infiltration, probably resulting from the 1944 infection. Unfortunately, no urethroscopy was possible at the time of diagnosis, and it was not felt to be desirable in the Out-patients' Department to perform a meatotomy. When the meatus was sufficiently dilated to admit the smallest cannula available, the patient departed.

Such cases are rare. Only one is recorded, so far as I can trace, in the literature : McLachlan in 1943 described a case of stricture formation occurring two years after successful chemotherapy. Nevertheless, such cases may be less rare than is imagined: the patients may not report to a venereologist, but be referred to a genito-urinary surgeon.

This case, moreover, provides good reason for deploring the use of chemotherapy by ships' officers and others without adequate instruction of the patient as to the necessity for subsequent surveillance and tests of cure (including urethroscopy), as soon as a port is reached in which these facilities are available.

I am indebted to Dr. R. H. Parry, Medical Officer of Health for the City and Port of Bristol, for permission to publish this case record.

Bristol and Avonmouth

D. T. RICHARDS, M.R.C.S., L.R.C.P., D.P.H.

REFERENCE

McLachlan, A. E. W. (1943) Brit. J. vener Dis., 19, 181.

\title{
LEAFLETS ON THE TREATMENT OF VENEREAL DISEASES OF THE EARLY NINETEENTH CENTURY
}

\author{
By A. FESSLER, F.R.C.S., L.R.C.P., M.D. (Vienna) \\ Venereal Diseases Officer, Lancashire County Council
}

Mr. R. Sharpe France, Archivist of the Lancashire County Council, kindly drew my attention to a collection of cuttings and leaflets, which had been deposited by Sir Roger Hulton, Bt., in the County Record Office. The collection containsbesides a large variety of items, such as political pamphlets, invitations to shareholders meetings, announcements of auctions, sales, shows and so forth-a number of leaffets dealing with the treatment of venereal disease. The leaflets, which 'were all jissued in London, are not dated. Nevertheless, with the help of those parts of the collection which are dated and by inference from the style of printing, it seems to be possible to state with a fair amount of accuracy that the leaflets were printed in the first two decades of the nineteenth century. Six of the leaflets were published by "Doctors", namely by "Dr. Eady", "Doctor Harvey", "Drs. C. and J. Jordan', "'Dr. Lamert, Senior", and "Dr. Matthews"; the collection contains two different types of leaflet issued by "Dr. Lamert, Senior"'. The remaining two leaflets were published by "Surgeons": "Messrs. Sloans \& Co.", and Messrs. "Tho. Taylor and Son"; the latter stress the fact that their names are on the "List of regular Surgeons published annually by the Royal College',.

The leaflets provide interesting and amusing reading from the medical and from the social points of view. "After the time of John Hunter's unfortunate selfexperiment in 1767, the dogma of the unity of syphilis and gonorrhoea was dominant until the publication of Ricord's Monographie du chancre in 1837; it is therefore easy to understand why. Dr. Eady and his colleagues do not distinguish between the two infections. One gets the impression, however, that 